\title{
Aprendizagem enquanto produção conjunta de conhecimento: avançando tarefas e alcançando entendimentos satisfatórios na fala-em-interação
}

\section{Learning as Joint Production of Knowledge: Advancing Tasks and Achieving Satisfactory Understandings in Talk-in-Interaction}

\author{
Andréia Kanitz* \\ Universidade Federal do Rio Grande do Sul \\ Porto Alegre - Rio Grande do Sul / Brasil \\ Ingrid Frank** \\ Universidade Federal do Rio Grande do Sul \\ Porto Alegre - Rio Grande do Sul / Brasil
}

\begin{abstract}
RESUMO: Esta pesquisa parte do entendimento de aprendizagem como produção conjunta de conhecimento que é tornada pública na medida em que participantes dão conta de um objeto de aprendizagem emergente de suas atividades (ABELEDO, 2008). Analisa-se um segmento interacional em que pesquisadores de um laboratório de engenharia produzem conhecimento em conjunto. Argumenta-se que, nesse segmento, os participantes tornam relevante, em suas açôes, dois componentes dessa produção que não aparecem na definição de Abeledo (realizada em cenário escolar): (i) a produção de um avanço relevante para o andamento das tarefas concretas em que estão engajados; e (ii) a satisfação com o que construíram em conjunto. A descrição realizada contribui com a discussão acerca de modos de organização e de fomento de instâncias de produção conjunta de conhecimento em cenário de sala de aula por meio de tarefas concretas que orientem e mobilizem os participantes em torno de um empreendimento comum. PALAVRAS-CHAVE: aprendizagem, fala-em-interação, produção conjunta de conhecimento, interação em sala de aula.
\end{abstract}

ABSTRACT: This research is based on the understanding of learning as joint production of knowledge that is made public as participants deal with an object that emerges from their activities (ABELEDO, 2008). We analyze a segment of

\footnotetext{
*andreiakanitz@hotmail.com

**dinyfrank@hotmail.com
} 
interaction in which researchers of an engineering laboratory produce knowledge together. In this segment, it is argued that participants, through their actions, relativize two components of this production that do not appear in Abeledo's definition (based on a school setting): (i) the production of an advance for the progress of the concrete activities in which they are engaged and (ii) the satisfaction of the participants with what they have built together. The description contributes with a discussion on the ways of organizing and promoting instances of joint production of knowledge in the classroom through concrete tasks that guide and mobilize participants around a common enterprise.

KEYWORDS: learning, talk-in-interaction, joint production of knowledge, classroom interaction.

\section{Introdução}

Este trabalho se insere no campo de pesquisas interessadas em descrever como as pessoas aprendem em conjunto por meio do uso da linguagem em interação. Parte-se de uma compreensão local e situada da organização social (GARFINKEL; 1967; LYNCH, 1993) bem como da aprendizagem (LAVE; WENGER, 1991; MONDADA; DOEHLER, 2004; ABELEDO, 2008), o que permite a investigação desse fenômeno enquanto uma realização prática, pública e emergente das ações coordenadas de participantes de atividades situadas.

Ancorados nessa visão praxiológica, com raízes na etnometodologia, trabalhos recentes desenvolvidos pelo Grupo de Pesquisa Interação Social e Etnografia (Grupo ISE), ${ }^{1}$ ao qual este estudo se vincula (GARCEZ, 2010), têm observado práticas de organização de salas de aula em cenários escolares diversos, em que os participantes demonstram e refletem um entendimento de aprendizagem não como um processo individual, instanciado no cérebro dos aprendizes, mas enquanto produção de conhecimento realizada conjuntamente (GARCEZ, 2007). Dentre esses trabalhos, Abeledo (2008) - mediante a observação de interações entre participantes de uma sala de aula de espanhol como língua adicional - articulou uma compreensão de aprendizagem como:

(a) uma realização pública, intersubjetiva, emergente e contingente, produzida para os fins práticos das atividades desenvolvidas em cada interação; (b) observável nos métodos que constituem o trabalho dos participantes para produzir essa realização, que não são generalizáveis, mas adequados a um contexto e a identidades que eles reflexivamente instauram - institucionais ou não -, e a objetos de aprendizagem que

${ }^{1}$ http://www.grupoise.blogspot.com 
eles definem e tornam relevantes; e (c) que produz relações de participação e pertencimento, já que implica a produção pública e intersubjetiva de competência para participar em atividades levadas a cabo em uma comunidade. (ABELEDO, 2008, p. 6).

Partindo desse entendimento de aprendizagem, outros trabalhos desenvolvidos no âmbito do grupo ISE investigaram cenários escolares diversos e descreveram como esses participantes se organizam para aprender - mediante observação minuciosa do que eles tornaram relevante em suas ações (GARCEZ, 2007; SCHULZ, 2007; BULLA, 2007; SALIMEN, 2009; LANGE, 2010). Esse conjunto de descriçōes revela que grande parte das atividades voltadas para a produção de conhecimento que ocorrem na sala de aula se organizam em torno do que é proposto por um dos interagentes (o professor), sendo que os demais participantes tendem a orientar-se para ele como o detentor de um status de conhecimento superior.

Tendo como ponto de partida os achados e avanços desses estudos realizados em cenários escolares, o presente trabalho tem como objetivo enfatizar o entendimento de aprendizagem enquanto produção conjunta de conhecimento e observar como ela ocorre em um cenário distinto da sala de aula, de modo a trazer novos olhares e contribuiçóes para esses estudos. O cenário investigado é um laboratório de engenharia em que os pesquisadores organizam-se interacionalmente para o desenvolvimento de tecnologia de ponta ${ }^{2}$ sem que haja um participante que detenha de antemão o conhecimento que se pretende alcançar ou que atue como um organizador das atividades que ali ocorrem.

Sustenta-se que os participantes do segmento de interação analisado produzem conhecimento conjuntamente à medida que dão conta das demandas de seu projeto de pesquisa, sendo os problemas emergentes desse projeto os responsáveis por mobilizar os participantes a se engajarem nessa produção de conhecimento. Além disso, argumenta-se que, nesse segmento, os participantes se orientam para dois componentes da atividade de produzir conhecimento que podem complementar a definição de Abeledo (2008):

${ }^{2}$ O Centro de Tecnologia, do qual faz parte o Laboratório de Transformação Mecânica, campo de pesquisa desta investigação, está ligado ao Programa de PósGraduação em Engenharia de Minas, Metalúrgica e de Materiais da Escola de Engenharia da Universidade Federal do Rio Grande do Sul, que tem conceito 7, nível de excelência, na avaliação da CAPES (ver <http://www.ufrgs.br/ppgem/por/ conteudo/institucional.asp $>$ ). 
(i) a produção de um avanço relevante para o andamento da atividade em que os participantes se engajam e (ii) a satisfação com o que eles construíram em conjunto.

A próxima seção deste trabalho é dedicada à explicitação dos pressupostos teóricos que o embasam. São apresentadas as raízes etnometodológicas de estudos interessados no caráter radicalmente local e situado da construção de entendimentos conjuntos e são discutidos alguns estudos que, ancorados nessa tradição de pesquisa, investigam ambientes de trabalho e laboratórios de produção de entendimentos conjuntos. A partir disso, são destacadas as contribuições relevantes desses trabalhos para a investigação da produção conjunta de conhecimento na expectativa de que a investigação de cenários de produção de conhecimento alheios à sala de aula possa contribuir para o andamento das discussões acerca de aprendizagem e produção de conhecimento na fala-eminteração de sala de aula.

\section{A perspectiva etnometodológica sobre as estruturas das organizações sociais}

A etnometodologia é um programa de pesquisa sociológica que foi articulado por Garfinkel (1967) com o objetivo de contrapor-se a pressupostos de estudos sociológicos que vigoravam na época, sobretudo à teoria sistêmica da ação social desenvolvida por Parsons (1937). Garfinkel criticou a ideia subjacente a tais estudos de que o olhar de pesquisadores externos, uma vez amparados pelo saber científico, forneceria uma perspectiva privilegiada sobre as açóes das pessoas comuns. De acordo com essa ideia, a ordem e a estrutura do mundo ordinário estariam fora do alcance de visão e de entendimento das pessoas comuns, sendo parte de uma estrutura formal maior apenas compreensível e explicável olhar externo de cientistas. Assim, era como se "mãos" ocultas fossem as responsáveis por animar a ação das pessoas, sendo que o trabalho de cientistas seria "revelar" essa estrutura formal descrevendo-as por meio de categorias científicas préformuladas (LYNCH, 1993).

Em oposição a tais premissas, o projeto da etnometodologia é revelar as estruturas locais de ação e racionalidade prática que as pessoas utilizam ao organizar suas ações cotidianamente. $\mathrm{O}$ foco, portanto, assenta-se na organização das tarefas, identidades e contextos enquanto produções dos próprios indivíduos, que, ao engajarem-se em açóes conjuntas, organizam, produzem e refletem seus entendimentos locais. Nesse sentido, em lugar da concepção de uma estrutura rígida, formal, com poderes superiores para coagir e organizar as pessoas, a 
etnometodologia aponta a fala-em-interação como o lugar primordial em que a ação e a ordem social são produzidas pelas pessoas. Suspende-se, portanto, o privilégio profissional de revelar as estruturas formais da ação e da ordem social segundo categorias científicas preestabelecidas pelo analista, e passa-se a observar como a ordem é estabelecida pelas açóes dos participantes.

\section{Uma perspectiva local e situada de como as pessoas se organizam para produzir conhecimento}

As ideias desenvolvidas por Garfinkel foram utilizadas por estudos interessados em desvelar como se dá a produção de conhecimento em laboratórios de produção de ciência e em diferentes cenários de atuação profissional, onde o conhecimento é explicitamente construído e debatido (STIVERS; MONDADA; STEENSING, 2011, p. 2). Baseados nas ideias de Garfinkel, esses estudos privilegiam a observação atenta das ações dos participantes enquanto engajam-se em práticas cotidianas ao produzirem conhecimento.

Lynch (1993, p. 270) aponta que o grande "mantra" de pesquisas realizadas desde a perspectiva etnometodológica interessadas em como se dá a produção de conhecimento científico em laboratórios é a afirmação de que as ações que constituem o dia a dia dos pesquisadores são distintas do que é relatado em artigos e outras publicações em que divulgam seus achados. A observação de instâncias de ocorrência natural geradas nos laboratórios permite descrever as práticas rotineiras que constituem de fato o trabalho dos pesquisadores para produzir conhecimento, mas que jamais são relatadas em textos científicos. Lynch aponta que, ao contrário de uma visão oficial e idealizada de ciência como um saber defensável, produzido mediante práticas especiais reservadas a profissionais experientes, os estudos de laboratório descrevem a produção de conhecimento nos laboratórios como uma atividade cotidiana realizada mediante práticas vernaculares que constituem os entendimentos emergentes, situados e por vezes controversos entre os pesquisadores.

Exemplo disso é o estudo de Goodwin (1997), que questiona os achados de Berlin e Kay (1969), um dos mais influentes estudos na área da antropologia cognitiva, responsável pela proposição de uma infraestrutura universal subjacente a todos os sistemas de cores elaborados pelos seres humanos. Goodwin critica a proposta de Berlin e Kay justamente porque eles se detêm na descrição de um sistema formal sem olhar para as práticas de pessoas usando as nomenclaturas das cores de fato para dar conta de atividades concretas. 
Para sustentar essa crítica, Goodwin (1997) observa as atividades de uma equipe de geoquímicos engajados em monitorar o ponto de uma reação química que é reconhecível em uma cor específica: um determinado tom de preto denominado na literatura da área como jet black (GOODWIN, 1997, p. 119120). O autor observa que, ao longo dessa atividade, o trabalho de discriminar as colorações que a reação química vai tomando é colocado como uma tarefa com consequências práticas (o produto da reação vai ser usado em uma próxima etapa de seus projetos práticos; portanto, a reação deve produzir algo que vai funcionar). Devido a tais consequências práticas, o autor aponta que a própria atividade em que os participantes estão envolvidos é que estabelece parâmetros acerca do que vai contar como uma solução correta para a tarefa de identificação da coloração preta nessas circunstâncias específicas e para os propósitos em pauta (sendo que outras tarefas estabeleceriam outros parâmetros). Assim, o que conta como uma instância válida da categoria de cor é estabelecido dentro do mundo público socialmente constituído pela atividade desenvolvida entre aqueles participantes. A partir disso, o autor sustenta que a cor descrita na literatura científica como um determinado tipo de preto, para aqueles participantes, envolvidos naquela instância específica, não é uma questão pré-formulada, um universal desvinculado de contexto, mas "um julgamento problemático a ser criativamente realizado pela utilização de uma coleção de práticas de trabalho"3 (GOODWIN, 1997, p. 111, tradução nossa).

Whalen e Vinkhuyzen (2000) é outro estudo que, amparado na visão etnometodológica acerca de como se constitui a ordem social, também enfatiza as práticas dos participantes envolvidos em cursos específicos de ações situadas como o foco de análise. Ligados a uma empresa que desenvolve e fabrica máquinas como impressoras e faxes, os autores se voltam para o debate acerca da relação homem-máquina e lançam uma crítica a pesquisas que desenvolvem sistemas a serem utilizados por seres humanos mas que não olham para como ocorre a interação de fato entre homens e máquinas, limitando-se a analisar questôes técnicas do sistema isoladamente.

Baseados, então, numa perspectiva etnometodológica, os autores analisam um corpus de ligações geradas no call center da empresa com o objetivo de identificar possíveis problemas no design do sistema que instrui os atendentes durante o atendimento. O foco dos autores é o exame da

\footnotetext{
3 "A problematic judgment to be artfully accomplished through the deployment of a collection of systematic work practices."
} 
racionalidade de senso comum e as competências que os usuários e os atendentes trazem à tona ao utilizarem o sistema em sequências de ações concretas. Essa análise permite aos autores apontar, por exemplo, que o sistema em questão forçava o atendente a dirigir determinadas perguntas aos clientes, que não davam conta do problema que havia sido formulado conjuntamente pelos dois ao longo da ligação, criando dificuldades para a resolução do problema do cliente com sua máquina. Whalen e Vinkhuyzen (2000) sustentam, portanto, que o design do sistema utilizado pelo atendente ao receber ligações dos clientes deveria ser fundamentado nas práticas e nas competências desses participantes ao utilizarem o sistema, de modo a tornálo mais responsivo aos problemas práticos que eles precisam resolver fazendo uso do sistema em cursos de ação concretos.

De modo semelhante, Button e Sharrock (2000) criticam o fato de que diversos estudos sociológicos interessados na investigação de ambientes de trabalho por vezes dão conta de quase todos os aspectos envolvidos nesses cenários, menos do trabalho em si. Os autores sugerem, então, que o programa da etnometodologia voltado para tais ambientes constitui-se numa espécie de corretivo a essa tendência, pois volta a atenção para as contingências que são parte do processo de desenvolvimento de produtos e serviços em organizações de trabalho amplas e complexas, tais como as indústrias.

Assim, partindo do interesse em compreender os modos pelos quais o trabalho entre engenheiros é realizado concretamente, Button e Sharrock (2000, p. 65) caracterizam esse trabalho no âmbito dos projetos dos quais participam como uma sucessão de operações de resolução de problemas. Os autores analisam um breve episódio de um encontro matinal rotineiro de engenheiros envolvidos no desenvolvimento de uma máquina fotocopiadora. Nesse episódio, os participantes lidam com um relatório que reporta falhas no funcionamento de copiadoras já em processo de testagem e buscam, a partir desse relatório, compreender as causas de seu mau funcionamento. Trata-se de um episódio de resolução de problemas em que os engenheiros, de posse do relatório, coordenam suas ações e buscam, por meio do uso da linguagem, encontrar a causa que explique a falha no funcionamento das copiadoras para, em seguida, determinar uma possível ação de resolução da falha, pela orientação para a questão prática por excelência colocada por Garfinkel (1967, p. 12): "o que fazer a seguir?”. A partir disso, é possível acompanhar que os engenheiros veem-se colocados diante de um problema que trava e/ou compromete a continuidade de seus trabalhos no projeto de desenvolvimento da fotocopiadora. Isso lhes exige encontrar conjuntamente sua resolução pela busca de uma causa 
que explique a falha no funcionamento da máquina e que, assim, lhes permita tomar providências necessárias para o seguimento dos trabalhos.

A relevância dos achados de tais pesquisas assenta-se não só no fato de evidenciarem o caráter situado da organização social em cursos específicos de ação, mas também porque destacam as práticas vernaculares envolvidas no trabalho de produção conjunta de conhecimento em contextos em que produzi-lo é necessário e imprescindível, uma vez que é condição para o andamento das atividades, tarefas e projetos em que os participantes estão envolvidos.

É interessante notar que, em grande parte dos cenários de produção de conhecimento descritos nesses estudos, os participantes se organizam para essa produção de modo distinto ao que muitas vezes ocorre em espaços escolares, cujo objetivo é também (ou deveria ser) a organização de participantes para a produção de conhecimento. Em encontros escolares, no mais das vezes, cada aprendiz trabalha individualmente seguindo as instruções do participante que detém status de conhecimento superior, de modo que cada um chegue a um mesmo resultado, que já é conhecido por esse participante. Vale destacar que esse ponto de chegada é muitas vezes algo abstrato: um conhecimento desvinculado de contexto imediato e generalizável.

No entanto, em uma época em que o conhecimento é multifacetado, em que a informação se altera continuamente e em que diversidade e pluralidade de perspectivas são palavras de ordem, torna-se necessário que a escola forme pessoas não apenas aptas a reproduzir, mas também de produzir conhecimentos. Nesse sentido, é necessário que os participantes desse cenário sejam colocados em situações que os tornem capazes de levantar dados relevantes sobre a realidade, organizá-los e, sobretudo, inovar no modo de interpretá-los e de usá-los criativamente. Além disso, como participantes de uma sociedade complexa e multifacetada, os próprios alunos que estão hoje nas escolas relacionam-se de modo diferente com a informação e o conhecimento, mas a sala de aula, e o modo como ela disponibiliza o conhecimento, muitas vezes não comporta significado atual, presente para eles, o que dificulta a realização do que é solicitado em sala de aula somente pela consciência de suas consequências futuras (até porque isso é algo difícil de ser entendido por uma criança ou até por um adolescente).

Assim, esta pesquisa parte dos achados e descriçóes realizados em diferentes espaços escolares (GARCEZ, 2007; SCHULZ, 2007; BULLA, 2007; SALIMEN, 2009; LANGE, 2010) para investigar um cenário em que 
a produção de conhecimento é realizada segundo uma organização distinta: um laboratório de engenharia voltado ao desenvolvimento de tecnologia. Buscase, portanto, a partir da investigação, práticas vernaculares pelas quais os participantes organizam a produção conjunta de conhecimento nesse laboratório, contribuir com a discussão sobre modos como a escola pode se configurar para se adaptar às novas maneiras de lidar com o conhecimento e a informação, de modo a: (i) capacitar os alunos a produzir conhecimentos novos mediante o diagnóstico e a resolução de problemas práticos; (ii) fazer com que os alunos valorizem a aprendizagem pela satisfação e desejo de solucionar problemas e desafios presentes (e não desafios futuros colocados pelo mercado de trabalho).

Conforme apontado na introdução deste trabalho, parte-se da definição de aprendizagem proposta por Abeledo (2008). A autora - mediante a observação de interações entre participantes de uma sala de aula de espanhol como língua adicional - articulou uma compreensão de aprendizagem como: uma realização pública, produzida pelos participantes para dar conta localmente de atividades situadas. Partindo desse entendimento de aprendizagem, produzido a partir de investigação de um cenário escolar, busca-se observar em que medida o trabalho de produção de conhecimento implementado pelos participantes do Centro de Tecnologia investigado - em que não há um participante que conduz as açóes dos demais nem que sabe de antemão as respostas aos problemas colocados pelas demandas das tarefas do laboratório - se assemelha ou se distancia dessa descrição.

Tendo desenvolvido os pressupostos teóricos que amparam este estudo, a próxima seção contempla a descrição de suas etapas metodológicas. A seguir, é analisado um segmento de fala-em-interação em que os participantes se orientam para o trabalho de produção conjunta de conhecimento. Argumentase que esse trabalho constitui-se não apenas como (i) uma produção pública e emergente das açôes dos participantes dar conta das atividades em que se engajam; (ii) observável nos métodos situados que constituem esse trabalho, adequados a contextos, identidades e objetos de aprendizagem que eles tornam relevantes; e (iii) que produz relações de participação e pertencimento (ABELEDO, 2008); mas também como um trabalho (iv) em que é observável a produção de um avanço no entendimento dos participantes, que é decisivo para o andamento de seus projetos de pesquisa; sendo que esse avanço (v) produz, ao final, a satisfação dos participantes acerca do que construíram em conjunto. 


\section{Explicando em termos vernaculares o trabalho de fazer investigar um fenômeno social}

Os dados utilizados para a realização desta pesquisa foram gerados em um dos sete laboratórios ligados ao centro de tecnologia de uma universidade federal voltado à produção de materiais no âmbito metal e mecânico. ${ }^{4} \mathrm{Os}$ projetos do grupo de pesquisadores foco desta investigação concentram-se no desenvolvimento de materiais biomédicos biocompatíveis (que não ocasionam rejeição pelo corpo humano) por meio da metalurgia do pó. ${ }^{5}$

Partiu-se de um corpus de sessenta horas de gravações audiovisuais geradas no laboratório entre fevereiro e março de 2011. Esse corpus foi visualizado levando-se em consideração a pergunta norteadora da investigação: como os participantes demonstram uns para os outros que estão produzindo conhecimento conjuntamente? A partir disso, foi selecionado um segmento interacional com duração aproximada de 21 minutos em que os participantes demonstravam orientar-se para essa produção em suas ações.

O segmento foi transcrito de acordo com as convenções Jefferson de transcrição $^{6}$ (LODER, 2008), que permite a análise detalhada das ações dos participantes turno a turno. Além disso, foram acrescentados quadros de imagem capturados do arquivo de vídeo, o que auxilia a análise dos gestos, movimentos e olhares como constituintes das ações (BULLA, 2007; SALIMEN, 2009).

A análise privilegiou a perspectiva dos participantes acerca do que constroem em conjunto em suas ações sequencialmente organizadas. Cabe dizer que, por questões de limite de espaço, o segmento não é apresentado na íntegra. Optou-se por apresentar os excertos em que as atividades em que os participantes se engajam constituem, demonstravelmente, etapas cruciais para a questão colocada ao longo do segmento, isto é, os excertos que contemplam:

\footnotetext{
${ }^{4}$ Trata-se de um núcleo de pesquisa e de desenvolvimento de tecnologia no âmbito metal-mecânico vinculado ao PPG de conceito 7 , nível de excelência na avaliação da Coordenação de Aperfeiçoamento de Pessoal de Nível Superior (CAPES).

${ }^{5}$ Metalurgia do pó é um processo de fabricação que produz peças, em escala comercial, através da aplicação de pressão sobre pós-metálicos ou cerâmicos ultrafinos. Trata-se de um processo em franca expansão na atualidade. Por meio dele, é possível fabricar peças para praticamente todos os ramos da indústria.

${ }^{6}$ As convenções de transcrição Jefferson utilizadas nos excertos de transcrição reproduzidos aqui se encontram no ANEXO A.
} 
i) a emergência e o destaque do problema em que eles se engajam; ii) a negociação das possibilidades de resolução do problema; e iii) o entendimento acerca da solução do problema boa o suficiente para dar conta de seu projeto no laboratório.

\section{Enfrentando um problema - "a gente não tem como fazer isso ainda"; "isso o quê?" - até sua resolução - "vai ficar bom"; "é isso aí": construção conjunta de conhecimento na fala- em-interação}

Dentre os diversos projetos de pesquisa em andamento no âmbito do laboratório investigado está o projeto que ambiciona produzir micropinças de biópsia para endoscopia por meio de um processo relativamente novo de moldagem de pós-metálicos por injeção. Trata-se de um processo em metalurgia do pó em que inicialmente um percentual de carregamento de pó metálico é misturado a um sistema aglutinante denominado sistema de binder (FIG. 1). Essa mistura é, então, injetada em um molde com a geometria da peça desejada (FIG. 2).

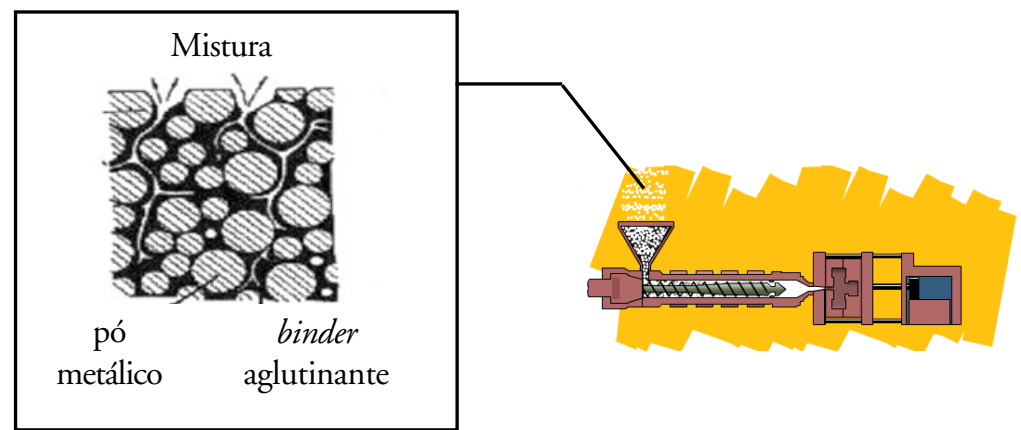

FIGURA 1 - Mistura composta por um carregamento de pó metálico e um sistema aglutinante (sistema de binder) que alimenta a injetora e forma as peças metálicas Fonte: Gusmão (2009, [s.p.]) e Boldani e Schaeffer (2008, [s.p.]).

\footnotetext{
${ }^{7}$ Sistema de binder: sistema aglutinante composto por pelo menos dois componentes químicos - em geral polímeros (ex. polietileno e polipropileno) e ceras (ex. parafina) - que cumpre a função de ligante entre as partículas de pó metálico. Os sistemas de binder podem variar em sua composição/formulação (os componentes químicos que o constituem) e na proporção de seus componentes.
} 


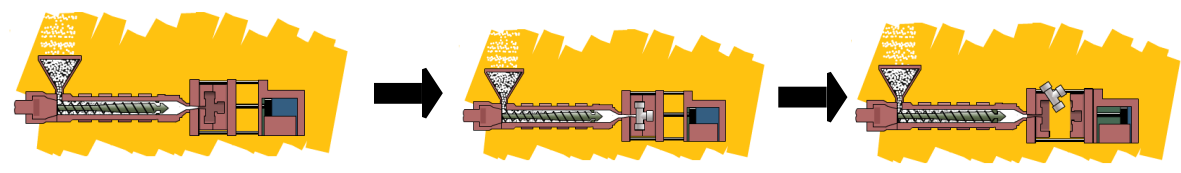

FIGURA 2 - Esquema do processo de injeção em uma injetora Fonte: Gusmão (2009, [s.p.]).

A obtenção de cargas injetáveis que apresentem bom desempenho no processo de injeção constitui etapa fundamental para o êxito da fabricação das peças. Em virtude disso, em um estágio anterior ao processo de injeção propriamente, estudos acerca de diferentes misturas - com diferentes percentuais de carregamento de pó metálico e com diferentes sistemas de binder - são realizados para fins de identificação dos parâmetros das melhores cargas para injeção.

No dado que analisamos nesta seção, as participantes Luana e Tatiana encontram-se nessa etapa que antecede o processo de injeção, dando início a um estudo em que buscam determinar os parâmetros composicionais das melhores cargas para a injeção das micropinças. Ao longo do segmento analisado, é possível acompanhar a orientação das participantes para o enfrentamento conjunto justamente do problema de delimitação (i) dos percentuais de carregamento de pó metálico e (ii) dos sistemas de binder que vão compor as misturas a serem analisadas para fins de identificação das melhores cargas.

Em meio a essa empreitada, elas buscam estabelecer quais serão os percentuais de carregamento de pó metálico ${ }^{8}$ que vão compor as misturas (40\%, 50\%, 60\%, 70\%); quantos sistemas de binder 9 serão utilizados para serem misturados aos diferentes percentuais de carregamento de pó metálico; quais serão os componentes aglutinadores utilizados para compor o(s) sistema(s) de binder (polipropileno [PP], polietileno [PE], parafina, ácido esteárico...). Mais precisamente, as participantes buscam definir, ao longo do segmento interacional, se na composição das misturas vão:

\footnotetext{
${ }^{8} \mathrm{Na}$ interação, as participantes referem-se aos percentuais de carregamento de pó metálico utilizando também os termos carregamento, carregamento de pó, pó metálico, pó ou porcentagem de pó.

${ }^{9} \mathrm{Na}$ interação, as participantes referem-se a sistema de binder utilizando também o termo binder apenas.
} 
variar os percentuais de carregamentos de pó metálico e fixar um sistema de binder (fixando os seus componentes);

fixar um percentual de carregamento de pó metálico e variar os sistemas de binder (variando os seus componentes em cada um dos sistemas);

variar os percentuais de carregamento de pó metálico e os sistemas de binder;

fixar um sistema de binder (fixando os seus componentes) ou variar três sistemas de binder (variando os seus componentes em cada um dos sistemas);

fixar um sistema de binder (fixando seus componentes) e variar apenas a proporção dos seus componentes majoritários/primários ${ }^{10}$ na mistura.

No início do segmento, Luana e Tatiana estão afastadas, cada uma trabalhando em sua mesa. Tatiana pergunta se Luana leu o artigo que ela havia indicado como referência para a definição do modo como elas poderiam proceder no estudo que estão iniciando. Luana, que está lendo o artigo em sua mesa, responde que está examinando o texto e, após cerca de dois minutos, ainda olhando para o artigo em sua mesa, afirma que elas ainda não têm como adotar os mesmos procedimentos utilizados no estudo referido. É nesse momento que Tatiana levanta de sua cadeira e segue até a mesa de Luana, onde as participantes passam a lidar com um objeto de conhecimento que elas próprias tornam relevante na sequência da interação: como constituir as misturas - de carregamentos de pó metálico e de sistemas de binder - a serem utilizadas no estudo de identificação das melhores cargas a serem injetadas para a produção das micropinças. Isso é o que acompanhamos a partir do excerto 1 abaixo.

\section{Excerto 1:}

$\begin{array}{lll}01 & \text { Luana: } & \text { a gente não tem como fazer isso ainda } \\ 02 & & (0,9) \\ 03 & \text { Tatiana: } & \text { isso o quê? } \\ 04 & & (.) \\ 05 & \text { Luana: } & \text { >que que eles fizeram.< eles fizeram três } \\ 06 & & \text { misturas com sessenta por cento de pó::, } \\ 07 & \text { Tatiana: } & \text { m.hm }\end{array}$

${ }^{10}$ Os componentes majoritários ou primários de um sistema de binder são os componentes em maior quantidade na composição. No dado aqui analisado, os componentes majoritários/primários referidos pelas participantes são o polietileno e o polipropileno. 


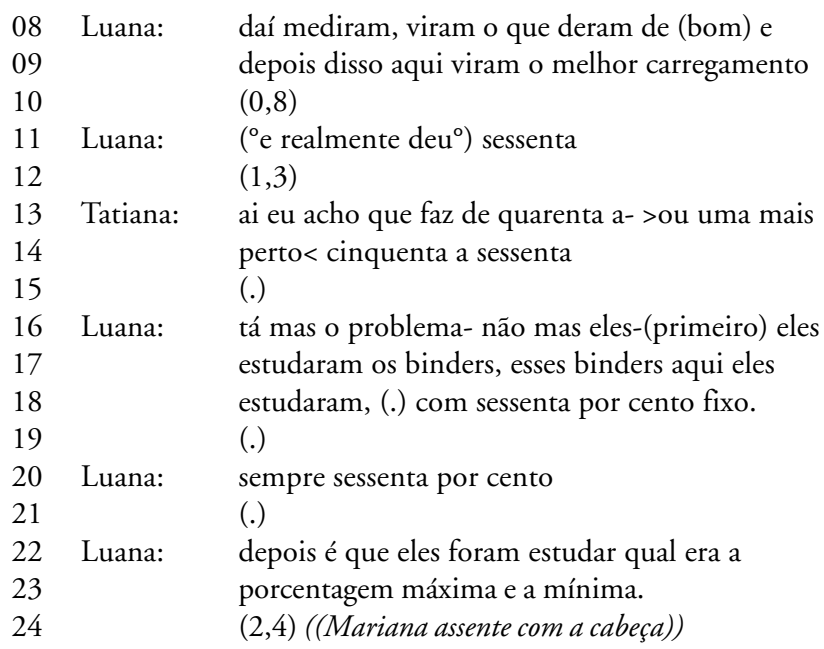

Depois de afirmar que não teriam como realizar o mesmo procedimento adotado no estudo referido ("a gente não tem como fazer isso ainda", linha 1) e de subsequentemente ser solicitada por Tatiana a esclarecer tal fato ("isso o quê?", linha 3), Luana relata brevemente o experimento apresentado no artigo. Segundo ela, os autores realizaram primeiramente um estudo para determinar o melhor sistema de binder, o que fizeram compondo três misturas variando três sistemas de binder diferentes e mantendo fixo o percentual de carregamento de pó metálico (60\%): ">que que eles fizeram.< eles fizeram três misturas com sessenta por cento de pó::, daí mediram, viram o que deram de (bom)”, e que, somente depois, realizaram um estudo para determinar o melhor percentual de carregamento de pó metálico ("depois disso aqui viram o melhor carregamento", linha 9), que, de fato, teria ficado em torno de $60 \%$ : "( ${ }^{\circ}$ e realmente $\left.\mathrm{deu}^{\circ}\right)$ sessenta", linha 11.

Tatiana, então, sugere que elas procedam de modo diferente, variando o percentual de carregamento de pó metálico na mistura entre cinquenta a sessenta por cento ("ai eu acho que faz de quarenta a- > ou uma mais perto< cinquenta a sessenta", linhas 13-14). Frente a isso, Luana volta a mencionar o problema da impossibilidade de se basearem no estudo relatado uma vez que ele investigou o melhor sistema de binder e não o melhor percentual de carregamento de pó metálico na mistura - interesse do estudo delas até este momento: "tá mas o problema- não mas eles estud- eles estudaram os binders, esses binders aqui eles estudaram com sessenta por cento fixo." (linhas 16-18).

Diante disso, Tatiana concorda com sua interlocutora (linha 24) e, conforme acompanhamos no excerto 2 , abaixo, demonstra ponderar acerca do 
problema apontado por Luana (“pois é::", linha 25). Depois de uma pausa, a participante, então, sugere novamente que procedam de modo diferente ao que aparece relatado no artigo: primeiro, variando o percentual de carregamento de pó e mantendo fixo um sistema binder e, depois, variando os sistemas de binder e mantendo fixo um percentual de carregamento de pó.

\section{Excerto 2:}

$\begin{array}{lll}25 & \text { Tatiana: } & \text { pois é:: } \\ 26 & & (0,9) \\ 27 & \text { Tatiana: } & \text { mas (na real) eu acho que tinha que pegar } \\ 28 & & \text { e fazer primeiro variando o pó e deixando o } \\ 29 & & \text { binder fixo. } \\ 30 & & (0,5) \\ 31 & \text { Tatiana: } & \text { e depois variando o binder e deixando o pó } \\ 32 & & \text { [fixo } \\ 33 & \text { Luana: } & \text { [tá mas daí dá pra fazer os dois ao mesmo } \\ 34 & & \text { tempo } \\ 35 & \text { Tatiana: } & \text { é }\end{array}$

Luana propõe, então, com base na sugestão apresentada, que seja possível proceder do modo como a sua interlocutora sugeriu realizando a variação dos carregamentos de pó metálico e dos sistemas de binder ao mesmo tempo, proposta com a qual sua interlocutora concorda inicialmente: "tá mas daí dá pra fazer os dois ao mesmo tempo"; "é" (linhas 33-35). As participantes chegam, assim, a um entendimento comum sobre o que parece ser o melhor procedimento para a continuidade de seu estudo das melhores cargas para injeção (QUADRO 1).

\section{QUADRO 1}

Entendimento inicial alcançado pelas participantes acerca de como proceder na composição das misturas

Proposta inicial de Luana e Tatiana

\section{Compor as misturas:}

$\rightarrow$ Variando os percentuais de carregamentos de pó metálico $(50 \%, 60 \%, 70 \% \ldots)$ e mantendo fixo um sistema de binder, isto é, mantendo fixos seus componentes.

$\rightarrow$ Mantendo fixo o percentual de carregamento de pó metálico ( $60 \%$ por exemplo) e variando os sistemas de binder, isto é, variando os componentes em cada um dos sistemas de binder.

Fonte: Elaboração própria. 
O entendimento alcançado ao final do segundo excerto, no entanto, não se mantém na sequência da interação, a partir do momento em que Luana inicia um esboço de como elas poderiam proceder na composição das misturas para o estudo em questão, conforme acompanhamos no excerto 3 abaixo:

\section{Excerto 3:}

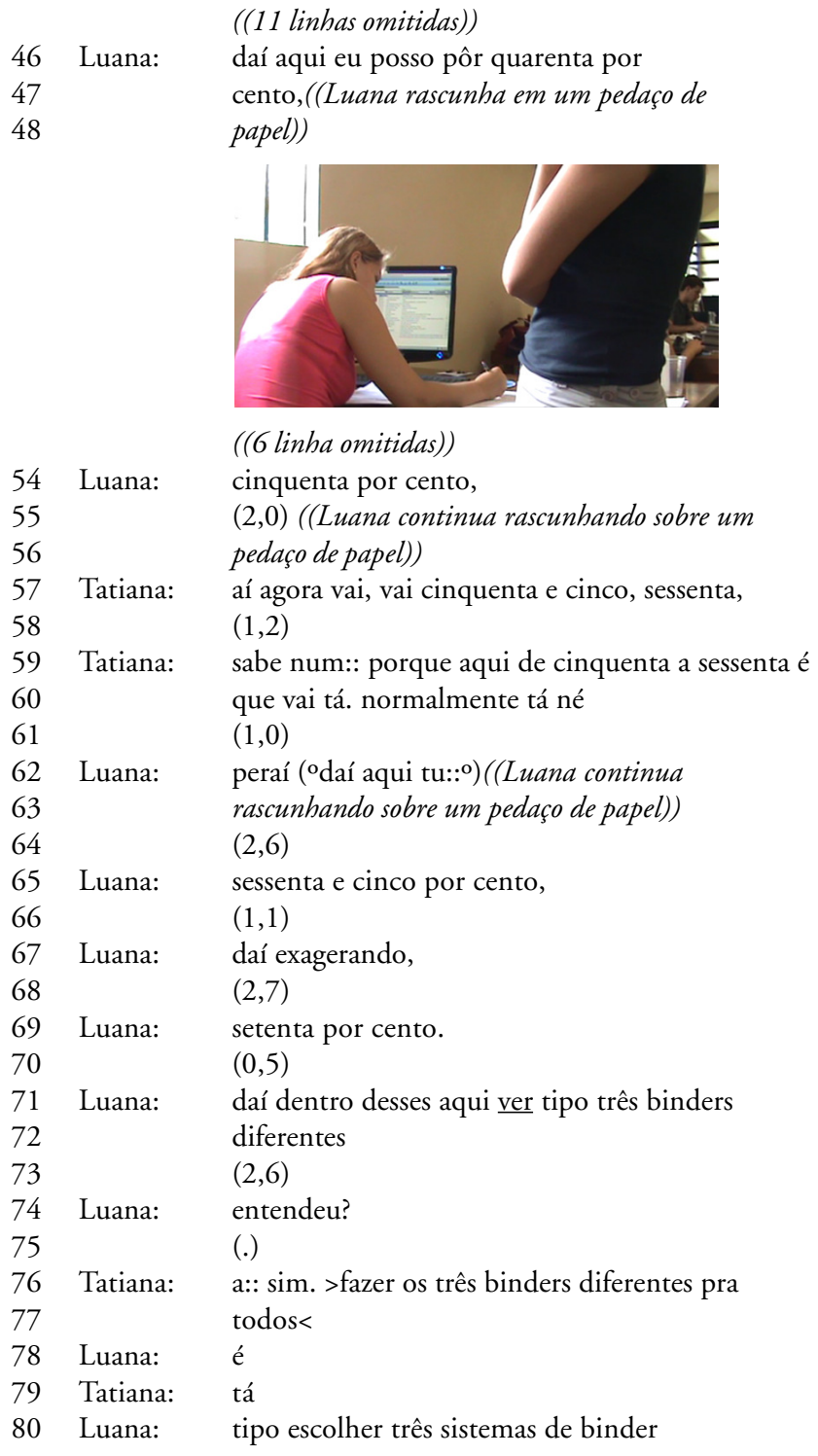


Em uma folha de papel, Luana passa a registrar sua proposta de variação percentual dos carregamentos de pó metálico nas misturas, variando entre quarenta e setenta por cento, distribuição com a qual Tatiana demonstra concordar ao, nas linhas 57-60, dar continuidade ao que sua interlocutora vinha propondo ("aí agora vai, vai cinquenta e cinco, sessenta, sabe num:: porque aqui de cinquenta a sessenta é que vai tá. normalmente tá né”). Em seguida, então, Luana propõe que a cada percentual de carregamento de pó sejam misturados três sistemas de binders diferentes cada qual com componentes distintos ("daí dentro desses aqui ver tipo três binders diferentes") (QUADRO 2).

\section{QUADRO 2}

Proposta apresentada por Luana acerca de como proceder na composição das misturas

\section{Proposta de Luana}

\section{Compor as misturas:}

$\rightarrow$ Variando os percentuais de carregamentos de pó metálico (de 40\% a 70\%) e

$\rightarrow$ variando os sistemas de binder, isto é, usando três sistemas de binder diferentes, cada qual com componentes distintos.

Fonte: Elaboração própria.

Depois de, então, esboçar no papel a sua proposta de composição das misturas, na linha 74, Luana verifica se Tatiana compreendeu a sua sugestão (“entendeu?"). No turno imediatamente seguinte, sua interlocutora expõe seu entendimento ("a:: sim. > fazer os três binders diferentes pra todos<", linhas 76-77), que é confirmado por Luana logo a seguir ("tipo escolher três sistemas de binder", linhas 78 e 80).

Frente à proposta de sua interlocutora, logo em seguida (excerto 4, abaixo), Tatiana, no entanto, propõe, diferentemente, que se componham as misturas fixando um único sistema de binder e variando três carregamentos de pó metálico com porcentagens diferentes (QUADRO 3). No entanto, Luana discorda da proposta apresentada por sua interlocutora ("ai não", linha 85).

\section{Excerto 4:}

$\begin{array}{lll}82 & \text { Tatiana: } & \text { na moral (cobrir) um sistema de binder mas } \\ 83 & & \text { com três porcentagens diferentes } \\ 84 & & (1,2) \\ 85 & \text { Luana: } & \text { ai não } \\ 86 & & \text { (.) }\end{array}$


87 Tatiana: por que não?

$88 \quad(1,5)$

89 Tatiana: eu- eu na minha cabeça faria assim

90 (.)

91 Tatiana: entendeu? $>$ porque $<$ daí tu vai saber o efeito porque

92 se tu mudar os binders em cada uma das porcentagens

93 aí tu não vai saber o efeito de nada em nada.

\section{QUADRO 3}

Contraproposta apresentada por Tatiana acerca de como proceder na composição das misturas

\section{Contraproposta de Tatiana}

\section{Compor as misturas:}

$\rightarrow$ Variando os percentuais de carregamentos de pó metálico $(50 \%, 60 \%, 70 \% \ldots)$ e

$\rightarrow$ mantendo fixo um sistema de binder, isto é, usando um único sistema de binder mantendo fixos os seus componentes.

Fonte: Elaboração própria.

Após o turno discordante de Luana, Tatiana questiona sua interlocutora ("por que não?", linha 87) e reitera sua proposta, na linha 89 ("eu- eu na minha cabeça faria assim”). Sem uma resposta de Luana, Tatiana argumenta que procedendo do modo como Luana sugeriu, variando os sistemas de binder em cada um dos carregamentos de pó metálico, não seria possível avaliar efeito algum (linhas 91-93).

$\mathrm{Na}$ sequência da interação, em trecho da interação omitido (linhas 94175), Luana passa a defender sua opção por utilizar três sistemas de binder diferentes cada qual com componentes distintos, argumentando ter sido esse o procedimento utilizado pelos autores do estudo relatado no artigo e que, sendo assim, não saberia como fixar um único sistema de binder. Diante do desconhecimento acerca desse aspecto demonstrado por Tatiana, as duas participantes passam a verificar as informações do artigo em conjunto e se certificam que, de fato, os autores do experimento referido utilizaram três sistemas de binder diferentes cada qual com componentes distintos. Logo após, Luana volta a expor sua ideia a sua interlocutora (excerto 5): 


\section{Excerto 5:}

\begin{tabular}{|c|c|c|}
\hline & & ((83 linhas omitidas) $)$ \\
\hline 176 & Luana: & tô pensando em fazer isso aqui ó. \\
\hline 177 & & $(2,4)$ \\
\hline 178 & Tatiana: & $\left({ }^{\circ}\right.$ é tem um outros $\left.{ }^{\circ}\right)(($ olhando para o artigo $))$ \\
\hline 179 & Luana: & três formulações diferentes aqui dentro, três \\
\hline 180 & & formulações diferentes aqui, três formulaçōes \\
\hline 181 & & aqui dentro, três formulações diferentes. \\
\hline 182 & & ((apontando para os carregamentos de pó metálico \\
\hline 183 & & no pedaço de papel em que estava rascunhando)) \\
\hline 184 & & $(1,8)$ \\
\hline 185 & Tatiana: & é. também dá, mas depois $>$ por exemplo $<$ tu vai \\
\hline 186 & & ter ainda mais dado para comparar ainda \\
\hline 187 & Luana: & nossa. daí não dá.= \\
\hline 188 & Tatiana: & $=e^{\prime}=$ \\
\hline 189 & Luana: & $=$ porque daí eu tô variando a porcentagem e tô \\
\hline 190 & & [ variando o negócio. $]=$ \\
\hline 191 & Tatiana: & [pois é. >isso que eu tô- isso que eu tô-<] \\
\hline 192 & Luana: & =é isso que eu não sei. \\
\hline 193 & & $(1,7)$ \\
\hline 194 & Luana: & ai ((suspira)) \\
\hline
\end{tabular}

Entre as linhas 176 e 183, Luana expõe novamente para Tatiana sua ideia já apresentada anteriormente de misturar três sistemas de binder cada qual com componentes distintos - "formulações diferentes" - a cada percentual de carregamento de pó metálico: "tô pensando em fazer isso aqui ó. três formulações diferentes aqui dentro, três formulações diferentes aqui, três formulações aqui dentro, três formulações diferentes". Logo em seguida, no turno das linhas 185-186, Tatiana concorda, então, que seja sim possível proceder dessa maneira na composição das misturas, apontando, no entanto, que isso resultaria em uma quantidade ainda maior de dados a serem comparados. No turno imediatamente seguinte, em contiguidade com o turno produzido por sua interlocutora, Luana imediatamente concorda com a ressalva de sua interlocutora ("nossa. daí não dá", linha 187; "porque daí eu tô variando a porcentagem e tô variando o negócio.", linhas 189-190) e demonstra não saber o que fazer: "é isso que eu não sei." (linha 192); "ai" (linha 194).

Duas propostas divergentes acerca de como proceder na composição das misturas colocam-se, assim, até este ponto da interação: de um lado, Luana propõe que, na composição das misturas, se varie os sistemas de binder; de outro lado, Tatiana sugere que se mantenha fixo nas misturas um único sistema de binder. Tatiana sustenta sua proposta argumentando que procedendo do modo como Luana sugeriu (variando os percentuais de carregamento de pó e 
os sistemas de binder) não seria possível avaliar efeito algum nas misturas. Além disso, Tatiana salienta que o procedimento sugerido por Luana resultaria em uma quantidade muito grande de dados para analisar. Luana, por sua vez, embora argumente inicialmente que a variação dos sistemas de binder foi o procedimento adotado no estudo referido no artigo e que, desse modo, não saberia como fixar um único sistema de binder com uma única composição, acaba, ao final do excerto 5, concordando com a consideração feita por sua interlocutora acerca da enorme quantidade de dados a serem analisados e comparados (QUADRO 4).

\section{QUADRO 4}

Propostas divergentes: a proposta de Luana e a contraproposta de Tatiana

Proposta de Luana

\section{Compor as misturas:}

- Variando os percentuais de carregamento de pó e

- Variando os sistemas de binder, isto é, usando três sistemas de binder diferentes cada qual com componentes distintos.

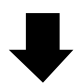

Problemas apontados por Tatiana com relação à proposta de Luana:

1. Impossibilidade de se avaliar algum efeito variando a composição dos sistemas de binder em cada percentual de carregamento de pó.

2. Grande quantidade de dados para analisar.
Contraproposta de Tatiana

\section{Compor as misturas:}

- Variando os percentuais de carregamento de pó e

- Mantendo fixo um sistema de binder, isto é, usando um único sistema de binder, mantendo fixos os seus componentes.
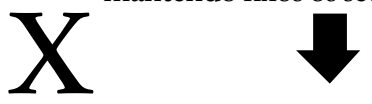

Problemas apontados por Luana com relação à proposta de Tatiana:

1. Dificuldade em fixar um único sistema de binder com uma composição fixa. Fonte: Elaboração própria.

Na sequência da interação, em trecho da interação omitido (linhas 195363), as participantes continuam discutindo em conjunto de que modo proceder na composição das misturas, na tentativa de chegar a um entendimento satisfatório acerca da melhor solução para o problema em questão. Ao longo de cerca de sete minutos, seguem avaliando diferentes possibilidades de solução do problema. No entanto, uma a uma, as propostas vão sendo postas em cheque por elas mesmas, e nenhuma solução consensual que lhes pareça satisfatória é alcançada. 
Diante dessa situação, num movimento de superação do problema diante do qual estão colocadas, Tatiana, retomando a proposta inicial de Luana, volta a afirmar que é possível encontrar bons resultados compondo misturas variando os sistemas de binder e os percentuais de carregamento de pó - mesmo não sendo possível justificá-los - e propõe a sua interlocutora, então, que considere apenas os bons resultados em seu trabalho, conforme acompanhamos no excerto 6 abaixo, linhas 364-371:

\section{Excerto 6:}

\section{((170 linhas omitidas))}

364 Tatiana: porque olha só. isso aqui $>$ se tu fizer todas as

365 misturinhas direitinho $<$ vai gerar resultados

366 bons

$367 \quad(1,8)$

368 Tatiana: >tu não vai saber por que $<$ mas gerou

$369 \quad(0,4)$

370 Tatiana: entendeu?, daí a partir desses:, >tu não vai

371 botar tudo isso no teu trabalho<

$372 \quad$ (.)

373 Luana: sim Tati eu sei mas eu tenho que estudar o

374 efeito de alguma coisa.

$375 \quad$ (.)

377 Luana: aqui $>$ com isso aqui $<$ eu estaria estudando o

378 efeito do carregamento do metal.=

379 Tatiana: =em diferentes composições de binder?

380 Luana: não. aí na mesma formulação de binder,=

381 Tatiana: =>tá mas [olha só<

382 Luana: [na mesma formulação em diferentes

383 proporções

((11 linhas omitidas))

395 Tatiana: então na composição fixa do binder, tu já vai

396 tá estudando o efeito do carregamento metálico

397 (.)

398 Tatiana: ou se tu quiser enxergar por outro lado, tu vai

399 tá estudando em diferentes carregamentos

$400 \quad$ metálicos diferentes binders

$401 \quad(0,7)$

402 Tatiana: tu pode estudar por um lado ou pelo outro.

403 (.)

404 Luana: é. só que- não. mas eu tenho que manter sempre

405 a formulação

406 Tatiana: sim. tu vai manter uma formulação

Embora Tatiana sugira que se proceda, então, do modo como Luana havia proposto anteriormente e, assim, legitime a proposta de sua interlocutora, 
Luana, no turno imediatamente seguinte, não ratifica a proposta de sua interlocutora e apresenta a necessidade de delimitar o estudo de modo a investigar o efeito de algo na composição das misturas ("sim Tati eu sei mas eu tenho que estudar o efeito de alguma coisa.", linha 373-374), o que não seria possível se variassem os sistemas de binder e os percentuais de carregamento de pó na composição das misturas a serem analisadas.

Diante da necessidade, levantada por Luana, de definir o propósito do estudo, as participantes passam, então, a avançar conjuntamente na resolução do problema de definição do modo como vão compor as misturas. Luana, depois de afirmar que o propósito do estudo seria estudar o efeito do carregamento de pó metálico nas misturas ("aqui >com isso aqui< eu estaria estudando o efeito do carregamento do metal.”, linhas 377-378), propõe, então, que se proceda ao estudo, aí sim, conforme sugerido inicialmente por Tatiana, mantendo fixo o sistema de binder na mistura ("não. aí na mesma formulação de binder”, linha 380), variando, no entanto, a proporção dos componentes na formulação: "na mesma formulação em diferentes proporçôes" (linhas 382-383).

Após onze linhas de transcrição omitidas, Tatiana sugere, então, que procedendo desse modo, Luana possa investigar tanto o efeito dos carregamentos de pó metálico - pela variação de seus percentuais - quanto o efeito do sistema de binder - pela variação na proporção de seus componentes: "então na composição fixa do binder, tu já vai tá estudando o efeito do carregamento metálico ou se tu quiser enxergar por outro lado, tu vai tá estudando em diferentes carregamentos metálicos diferentes binders tu pode estudar por um lado ou pelo outro." (linhas 395-402). Depois de confirmar e em seguida desconfirmar o entendimento formulado por sua interlocutora, Luana reitera que terá de manter fixos os componentes - "a formulação" - do sistema de binder ("é. só que- não. mas eu tenho que manter sempre a formulação", linhas 404-405), reiteração com a qual sua interlocutora concorda: "sim. tu vai manter uma formulação." (linha 406).

Isso posto, em trecho da interação omitido (linhas 407-452), as participantes passam a se engajar na escolha dos componentes para constituir o sistema de binder a ser utilizado nas misturas. Tatiana sugere que utilizem um dos sistemas de binder utilizado no experimento relatado no artigo. Assim, Luana, com base no artigo, propõe que componham o sistema de binder a ser mantido fixo nas misturas com quatro componentes: polipropileno, polietileno, parafina e ácido esteárico - escolha com a qual Tatiana concorda. 
Estabelecidos os componentes do sistema de binder, Luana retoma sua ideia de, então, fixar um sistema de binder, variando, no entanto, a proporção de seus componentes na mistura. Conforme acompanhamos no excerto 7 abaixo (linhas 453-465), a participante, com base no estudo relatado no artigo de referência, propõe que elas estudem a diferença de efeito entre os dois componentes majoritários/primários do sistema de binder fixado (o polipropileno e o polietileno), variando suas proporções na mistura.

\section{Excerto 7:}

\begin{tabular}{|c|c|c|}
\hline & & ((47 linhas omitidas $))$ \\
\hline 453 & Luana: & daí:: \\
\hline 454 & & $(0,7)(($ Luana verifica o artigo $))$ \\
\hline 455 & Luana: & variar que nem ele variou aqui ó \\
\hline 56 & & (.) \\
\hline 457 & Tatiana: & num ele usou quarenta por cento, \\
\hline 458 & & ( $>^{\circ}$ daí só fazer que nem ele $f e z^{\circ}<$ ) estudar a \\
\hline 459 & & diferença entre esses aqui ó entre o PP e PE \\
\hline 460 & & $(5,8)(($ Tatiana assente com a cabeça, olhando \\
\hline 461 & & para o artigo)) \\
\hline $\begin{array}{l}462 \\
463\end{array}$ & Luana: & $\begin{array}{l}\text { ele fixou a composição de parafina >olha o } \\
\text { que ele fez< ele fez isso aqui ó. }\end{array}$ \\
\hline 464 & Tatiana: & ãhã \\
\hline $\begin{array}{l}465 \\
466\end{array}$ & Luana: & $\begin{array}{l}\text { ele fixou a composição de parafina, e mudou os } \\
\text { outros. }\end{array}$ \\
\hline & & ((19 linhas omitidas $))$ \\
\hline 486 & Tatiana: & então tu tá estudando na verdade o efeito dos \\
\hline 487 & & componentes majoritários em diferentes \\
\hline 488 & & carregamentos de pó \\
\hline 489 & & $(0,6)$ \\
\hline $\begin{array}{l}490 \\
491\end{array}$ & Luana: & $\begin{array}{l}>\text { nã-< eu estaria estudando qual é me- é. } \\
(1,8)\end{array}$ \\
\hline 492 & Luana: & do:: do:: componente primário $=$ \\
\hline 493 & Tatiana: & $=e^{\prime}=$ \\
\hline 494 & Luana: & $=0$ efeito do componente primário pra:: >é isso \\
\hline 495 & & \\
\hline 496 & Tatiana: & \\
\hline
\end{tabular}

Tatiana concorda com a proposta de sua interlocutora (linhas 460 e 463) e, nas linhas 485-487, submete a ela o seu entendimento de que, então, o estudo teria um novo foco: não mais apenas o estudo do efeito do carregamento de pó metálico na mistura, mas o estudo do efeito dos componentes majoritários/ primários do binder (PP e PE) em diferentes carregamentos de pó metálico. Depois de inicialmente hesitar (">nã-< eu estaria estudando qual é me-é..", linha 489), Luana acaba confirmando o entendimento proposto por sua interlocutora 
acerca do novo propósito do estudo: “do:: do:: componente primário” (linha 491); "o efeito do componente primário pra:: >é isso aí<" (linhas 495-496).

Mediante esforços conjuntos, as participantes conseguem, finalmente, ao final desse segmento interacional, estabelecer um novo entendimento comum acerca de como proceder na composição das misturas pelo estabelecimento de um novo foco para o estudo e, assim, dar conta do problema que as impossibilitava de seguir adiante na investigação das melhores cargas para injeção. Interacionalmente, Tatiana e Luana negociam uma solução consensual, com a qual demonstram estar satisfeitas, que acaba por conciliar, em alguma medida, parte das propostas iniciais apresentadas por cada uma delas: (a) a ideia de manter fixo um único sistema de binder nas misturas (apresentada inicialmente por Tatiana) e (b) a proposta de realizar alguma variação na composição das misturas (apresentada ao longo da interação por Luana), não pela variação de três sistemas de binder distintos nas misturas, mas pela variação da proporção dos componentes fixados para compor o único sistema de binder a ser utilizado nas misturas.

Compor as misturas mantendo fixo um único sistema de binder, mas variando a proporção de polipropileno e de polietileno misturados aos diferentes percentuais de carregamentos de pó metálico é, então, a solução que as participantes alcançam para o problema colocado desde o início deste segmento interacional: como constituir as misturas para a realização do estudo de identificação das melhores cargas para a injeção das micropinças (QUADRO 5).

\section{QUADRO 5}

A proposta final negociada conjuntamente pelas participantes

\begin{tabular}{|c|c|}
\hline Proposta de Luana & Proposta de Tatiana \\
\hline Compor as misturas: & Compor as misturas: \\
\hline - Variando os percentuais de carregamento & - Variando os percentuais de carregamento \\
\hline de pó e & de pó e \\
\hline $\begin{array}{l}\text { - variando os sistemas de binder, isto é, } \\
\text { usando três sistemas de binder diferentes } \\
\text { cada qual com componentes distintos. }\end{array}$ & $\begin{array}{l}\text { - mantendo fixo o sistema de binder, isto é, } \\
\text { usando um único sistema de binder, } \\
\text { mantendo fixos os seus componentes. }\end{array}$ \\
\hline
\end{tabular}


Proposta acordada por Luana e por Tatiana

Solução encontrada pelas participantes:

Fixar um único sistema de binder e variar a proporção de seus componentes na mistura.

Compor as misturas:

- Variando os percentuais de carregamento de pó;

- mantendo fixo um único sistema de binder: usar um único sistema de binder, mantendo fixos os seus componentes (ideia de Tatiana);

A origem da referência não foi encontrada. variando, no entanto, a proporção dos componentes majoritários (PP e PE) na mistura (ideia de Luana).

Fonte: Elaboração própria.

Solucionado o problema, as participantes demonstram finalmente estar satisfeitas com a definição alcançada acerca do modo como proceder na composição das misturas para os fins de identificação do efeito dos componentes primários/majoritários do binder nos diferentes percentuais de carregamentos de pó metálico estabelecidos no início da interação (excerto 3). Depois de ainda estabelecerem como realizariam a variação dos percentuais de polietileno e polipropileno na composição, as participantes concluem a atividade e demonstram terem alcançado conjuntamente uma definição satisfatória para os seus propósitos situados, conforme acompanhamos no oitavo e último excerto abaixo: "vai ficar bom” (linha 543); "é isso â’” (linha 544).

\section{Excerto 8:}

\section{((35 linhas omitidas))}

532 Luana: e variar isso aqui ó. bota quarenta e não bota

533 nada nessa aqui. daí aqui bota nada dessa aqui

534 e quarenta dessa aqui.

535 Tatiana: sim

536 Luana: eaquibo[ta::

537 Tatiana: [faz uma equimolecular

538 Luana: é. ó:: bota vinte desse e vinte desse e aqui é

539 cinco por cento né

540 Tatiana: $\underline{e}$

541 Luana: e cinco desse

542 
543 Luana: >vai ficar bom $<=$

544 Tatiana: =é isso aí

545

(.)

Após esse segmento, as participantes passam a se orientar para as etapas seguintes do estudo em questão. Em momento posterior ao segmento aqui analisado, as participantes, com base na definição alcançada acerca do modo como vão compor as misturas, iniciam a etapa seguinte do estudo: o preparo das misturas propriamente. É, portanto, baseando-se no entendimento construído conjuntamente ao longo da interação aqui analisada que elas dão continuidade ao estudo e fazem avançar suas atividades no laboratório.

Engajadas na resolução do problema de definição do modo como compor as misturas para injeção, as participantes, queremos argumentar, produzem conhecimento conjuntamente na medida em que alcançam, naquele exato aqui-e-agora da interação, uma definição satisfatória que resolve o problema diante do qual estão colocadas. Ao longo do segmento analisado, Tatiana e Luana buscam, por meio de esforços interacionais conjuntos, dar conta de uma questão tornada relevante por elas próprias desde o início do segmento, e é mediante açóes sequencialmente organizadas que elas avançam e, por fim, alcançam um entendimento compartilhado de como proceder na constituição das misturas a serem estudadas.

Colocadas diante de um problema, as participantes conseguem, enfim, ao longo do extenso segmento de interação, superá-lo, dado que alcançam uma resolução satisfatória para os seus propósitos situados. Há, portanto, a produção conjunta de um avanço, visto que, diante da indefinição de como proceder na constituição das misturas, as participantes alcançam ao final da interação, mediante engajamento conjunto, uma definição compartilhada com a qual demonstram estar satisfeitas.

Nesses termos, o segmento interacional aqui analisado constitui uma sequência de produção conjunta de conhecimento, (i) em que Tatiana e Luana se engajam conjuntamente na interação para (ii) dar conta de um objeto (iii) tornado relevante por elas próprias num exato aqui-e-agora de uma interação (ABELEDO, 2008). Nessa empreitada, queremos argumentar, as participantes (iv) produzem conjuntamente um avanço pela superação do estado inicial em que não sabiam como dar conta do objeto de conhecimento tornado relevante que as impossibilitava de dar continuidade aos seus projetos, e (v) demonstram, ao final, estarem satisfeitas com esse novo entendimento/avanço alcançado. 


\section{Considerações finais}

Neste trabalho, foi destacado o entendimento de aprendizagem como produção conjunta de conhecimento. A partir da análise de um segmento de fala-eminteração entre pesquisadores em um laboratório de engenharia, sustentou-se que as participantes dessa interação produzem conhecimento conjuntamente à medida que dão conta dos problemas emergentes de tarefas concretas do laboratório. Assim, dando continuidade à discussão acerca de "como os múltiplos participantes criam condiçôes para a produção conjunta de conhecimento, que é legitimada como relevante entre eles" (GARCEZ, 2007, p. 31), argumentou-se que, nesse segmento, as participantes tornam relevante, em suas ações, dois componentes cruciais para essa produção que não aparecem na definição de aprendizagem apresentada por Abeledo (2008) a partir de dados de interação em ambiente escolar: (i) a produção de um avanço relevante para o andamento de seus projetos de pesquisa e (ii) a satisfação com o que construíram em conjunto.

É interessante notar que as participantes se engajam nessa atividade durante 21 minutos ininterruptos. Ao longo desse tempo, Luana e Tatiana solicitam informações uma para a outra, discordam da proposta uma da outra, sugerem uma solução para o problema colocado, concordam com o enunciado da outra, reparam suas falas, avaliam as contribuições uma da outra, etc. Tais açôes são implementadas para atender às demandas de tarefas concretas no laboratório. São essas tarefas concretas, portanto, as responsáveis por mover as ações das participantes. São essas tarefas, e as demandas colocadas por elas, que compelem Luana e Tatiana a manterem um foco de atenção conjunto e a lançarem mão de um vasto repertório de ações durante uma sequência que se estende por 21 minutos e que finaliza apenas quando as participantes chegam, finalmente, a um entendimento que ambas consideram satisfatório.

Portanto, acredita-se que a descrição realizada neste trabalho possa fornecer subsídios para se pensar e se refletir acerca de modos de organização e de fomento de instâncias de produção conjunta de conhecimento no cenário de sala de aula também por meio de tarefas concretas que orientem e mobilizem os participantes desse cenário em torno de um empreendimento comum. Espera-se, portanto, que esta pesquisa possa contribuir com argumentos que sustentem uma pedagogia centrada nos fazeres na sala de aula, voltada para tarefas que coloquem os participantes desses encontros em situações práticas que exijam deles atenção conjunta, engajamento, colaboração e responsabilidade mútua. Em outras palavras, uma pedagogia que lhes possibilite assumir o papel de, justamente, produtores do conhecimento. 


\section{Referências}

ABELEDO, M. de la O. L. Uma compreensão etnometodológica da aprendizagem de lingua estrangeira na fala-em-interação de sala de aula. 2008. $217 \mathrm{f}$. Tese (Doutorado em Letras) - Programa de Pós-Graduação em Letras, Universidade Federal do Rio Grande do Sul, Porto Alegre, 2008.

ATKInsON, J. M.; HERITAGE, J. (Org.). Structures of Social Action. Cambridge (UK): Cambridge University Press, 1984.

BERLIN, B.; KAY, P. Basic Color Terms: Their Universality and Evolution. Berkeley: University of California Press, 1969.

BOLDANI, P. O.; SCHAEFFER, L. Processo de moldagem de pós metálicos por injeção - uma revisão. 2008. Disponível em: <http://www.ufrgs.br/ldtm/ publicacoes/Art_Metalurgia.pdf>. Acesso em: 14 fev. 2012.

BULLA, G. S. A realização de atividades pedagógicas colaborativas em sala de aula de português como língua estrangeira. 2007. 127 f. Dissertação (Mestrado em Letras) - Programa de Pós-Graduação em Letras, Universidade Federal do Rio Grande do Sul, Porto Alegre, 2007.

BUTTON, G.; SHARROCK, W. Design by Problem Solving. In: LUFF, P.; HINDMARSCH, J.; HEATH, C. (Org.). Workplace Studies: Recovering Work Practice and Informing System Design. Cambridge (UK): Cambridge University Press, 2000. p. 29-45.

GARCEZ, P. M. A organização da fala-em-interação na sala de aula: controle social, reprodução de conhecimento, construção conjunta de conhecimento. Calidoscópio, São Leopoldo, v. 4, n. 1, p. 66-80, 2006.

GARCEZ, P. M. Fala-em-interação e comunidades de aprendizagem. Projeto de pesquisa submetido ao $\mathrm{CNPq}$ para renovação de Bolsa de Produtividade em Pesquisa. Manuscrito inédito. Porto Alegre, UFRGS, 2010. Manuscrito inédito. GARCEZ, P. M. Organização da fala-em-interação, participação e aprendizagem. Projeto de pesquisa submetido ao $\mathrm{CNPq}$ para renovação de Bolsa de Produtividade em Pesquisa. Porto Alegre, UFRGS, 2007. Manuscrito inédito. GARFINKEL, H. Studies in Ethnomethodology. Cambridge (UK): Polity, 1967. GOODWIN, C. The Blackness of Black: Color Categories as Situated Practice. In: RESNICK, L. et al. Discourse, Tools and Reasoning: Essays on Situated Cognition. New York: Springer, 1997. p. 111-140.

GUSMÃO, L. Injeção de plásticos e metais. 2009. Disponível em: <http:// www.ebah.com.br/content/ABAAAAALTcAI/injecao-plasticos-metais $>$. Acesso em: 14 fev. 2012. 
LANGE, C. P. Formulação e ensino-aprendizagem na fala-em-interação de sala de aula de Inglês como língua adicional na Educação de Jovens e Adultos. 2010. 168 f. Dissertação (Mestrado em Letras) - Programa de Pós-Graduação em Letras, Universidade Federal do Rio Grande do Sul, Porto Alegre, 2010.

LAVE, J.; WENGER, E. Situated Learning. Legitimate Peripheral Participation. Cambridge (UK): Cambridge University Press, 1991.

LODER, L. L. O modelo Jefferson de transcrição: convençōes e debates. In: LODER, L. L.; JUNG, N. M. (Org.). Fala-em-interação social: introdução à Análise da Conversa Etnometodológica. Porto Alegre: Mercado de Letras, 2008. p. $127-160$.

LYNCH, M. Scientific Practice and Ordinary Action: Ethnomethodology and Social Studies of Science. New York: Cambridge University Press, 1993.

MONDADA, L.; DOEHLER, S. P. Second Language Acquisition as Situated Practice: Task Accomplishment in the French Second Language Classroom. Modern Language Journal, v. 88, n. 4, p. 501-518, 2004.

OCHS, E.; SCHEGLOFF, E.; THOMPSON, S. Interaction and Grammar. Cambridge (UK): Cambridge University Press, 1996.

PARSONS, T. The Structure of Social Action. New York: McGraw-Hill, 1937.

SALIMEN, P. G. A atividade pedagógica de encenar em grupos na sala de aula de lingua estrangeira: pedidos de ajuda, ofertas de ajuda e aprendizagem. 2009. 155 f. Dissertação (Mestrado em Letras) - Programa de Pós-Graduação em Letras, Universidade Federal do Rio Grande do Sul, Porto Alegre, 2009.

SCHULZ, L. A construção da participação na fala-em-interação de sala de aula: um estudo microetnográfico sobre a participação em uma escola municipal de Porto Alegre. 2007. 164 f. Dissertação (Mestrado em Letras) - Programa de Pós-Graduação em Letras, Universidade Federal do Rio Grande do Sul, Porto Alegre, 2007.

STIVERS, T.; MONDADA, L.; STEENSING, J. Knowledge, Morality and Affiliation in Social Interaction. In: ____ (Org.). The Morality of Knowledge in Conversation (Studies in Interactional Sociolinguistics). Cambridge (UK): Cambridge University Press, 2011. p. 3-26.

WHALEN, J.; VINKHUYZEN, E. Expert Systems in (Inter)Action: Diagnosing Document Machine Problems over the Telephone. In: LUFF, P.; HINDMARSH, J.; HEATH, C. (Org.). Workplace Studies: Recovering Work Practice and Informing System Design. Cambridge (UK): Cambridge University Press, 2000. p. 92-140. 


\section{ANEXO A - Convenções de transcrição}

\begin{tabular}{|c|c|c|}
\hline . & (ponto final) & entonação descendente \\
\hline$?$ & (ponto de interrogação) & entonação ascendente \\
\hline , & (vírgula) & entonaçãoo de continuidade \\
\hline - & (hífen) & marca de corte abrupto \\
\hline$\uparrow \downarrow$ & $\begin{array}{l}\text { (flechas para cima e para baixo) } \\
\text { para cima; mais grave: para baixo) }\end{array}$ & alteração do tom de voz (mais agudo: \\
\hline$:$ & (dois pontos) & prolongamento do som \\
\hline$\underline{\text { nunca }}$ & (sublinhado) & som enfatizado \\
\hline PALAVRA & (maiúsculas) & fala em volume alto \\
\hline${ }^{\circ}$ palavra ${ }^{\circ}$ & (sinais de graus) & fala em voz baixa \\
\hline$>$ palavra $<$ & $\begin{array}{l}\text { (sinais de maior do que } \\
\text { e menor do que) }\end{array}$ & fala acelerada \\
\hline$<$ palavra $>$ & $\begin{array}{l}\text { (sinais de menor do que } \\
\text { e maior do que) }\end{array}$ & fala desacelerada \\
\hline hh & (série de h’s) & aspiração ou riso \\
\hline.$h h$ & (h's precedidos de ponto) & inspiração audível \\
\hline [] & (colchetes) & fala simultânea ou sobreposta \\
\hline$=$ & (sinais de igual) & elocuçōes contíguas \\
\hline$(2,4)$ & (números entre parênteses) & $\begin{array}{l}\text { medida de silêncio (em segundos } \\
\text { e décimos de segundos) }\end{array}$ \\
\hline (.) & (ponto entre parênteses) & micropausa, até $2 / 10$ de segundo \\
\hline() & (parênteses vazios) & $\begin{array}{l}\text { segmento de fala que não pôde ser } \\
\text { transcrito }\end{array}$ \\
\hline (palavra) & (segmento de fala entre parênteses) & transcrição duvidosa \\
\hline $\begin{array}{l}((\text { olhando } \\
\text { para o teto }))\end{array}$ & (parênteses duplos) & descrição de atividade não vocal \\
\hline
\end{tabular}

Fonte: Adaptado de Atkinson e Heritage (1984, p. ix-xvi), Ochs, Schegloff, e Thompson (1996, p. 461-465) e das instruçōes para submissão de artigos ao periódico especializado Research on Language and Social Interaction. 